\title{
Bilateral Involvement of Frontal Sinuses in a Pott's Puffy Tumor: A Case Report
}

\author{
José María Palacios-García ${ }^{1}$, Ramón Moreno-Luna², Elena Molina-Fernandez ${ }^{3}$, Serafin Sanchez-Gomez ${ }^{4}$
}

\begin{abstract}
Aim and objective: A case report with review of the literature.

Background: Pott's puffy tumor is an uncommon complication of frontal sinusitis. Nevertheless, an increase in the frequency of cases has been reported over the last 10 years. The presence of both frontal sinuses in the production of Pott's puffy tumor has never been described before. Case description: A 15-year-old boy was evaluated in the emergency department by tumor and pruritus at the right frontal level. A computed tomography (CT) scan revealed a disruption of the right frontal sinus with a subperiosteal abscess. During surgery, it was discovered the involvement of both frontal sinuses. A combined bilateral functional endoscopic sinus surgery and external approach were used.

Conclusion: This pathology must be kept in mind in the case of an adolescent patient with a frontal tumor. Surgery is the most important factor in the treatment of this pathology together with a targeted antibiotic treatment.
\end{abstract}

Keywords: Adolescent, Nasal surgery, Pott puffy tumor, Sinusitis complication.

Otorhinolaryngology Clinics: An International Journal (2019): 10.5005/jp-journals-10003-1340

\section{BACKGROUND}

The Pott's puffy tumor is an uncommon complication of frontal sinusitis. It was believed that the number of cases had decreased in the post-antibiotic era; nevertheless, an increase in the frequency of cases has been reported over the last 10 years. ${ }^{1}$ Therefore, it is important to have high diagnostic suspicion due to the high rate of intracranial extension that occurs in this pathology. ${ }^{2}$

We present a case report with an unusual presentation of a Pott's puffy tumor where both frontal sinuses were involved in its development.

\section{Case Description}

A 15-year-old boy with a personal history of appendectomy and amoxicillin allergy was evaluated in the emergency department by tumor and pruritus at the right frontal level of 48 hours of evolution. No trauma to the area or insect sting was referred. The patient had no fever or reported nasal obstruction or rhinorrhea. The lump was painful, well defined, elastic consistency, and fluctuating to the palpation, about $3 \times 2 \mathrm{~cm}$. Computed tomography (CT) scan of the skull was requested showing an inflammatory collection of $3.5 \times 1.8 \times 3.3 \mathrm{~cm}$ secondary to disruption of the right frontal sinus and spilling of its contents into the internal angle of the right orbit (Fig. 1). There was no intracranial or ocular affectation. Empirical antimicrobial treatment was started with clindamycin $600 \mathrm{mg}$ every 8 hours.

A 3D pre-surgical study of the CT was carried out objectifying two lesions at the level of the external table of the right frontal sinus (Fig. 2). The patient undergoes bilateral functional endoscopic sinus surgery (FESS) performing uncinectomy, anterior ethmoidectomy, maxillectomy, and opening of both frontal recesses (draft lla). Despite these maneuvers, the subperiosteal abscess was maintained at the right frontal level and an external modified Lynch-Howarth eyebrow incision approach was performed, evacuating the purulent content. As predicted in the $3 \mathrm{D}$ reconstruction, a double solution \begin{tabular}{l}
\hline${ }^{1-4}$ Department of Otorhinolaryngology, Hospital Universitario Virgen \\
Macarena, Sevilla, Spain \\
Corresponding Author: José María Palacios-García, Department of \\
Otorhinolaryngology, Hospital Universitario Virgen Macarena, Sevilla, \\
Spain, Phone: +34 9550080 00, e-mail: orlpalaciosgarcia@gmail.com \\
How to cite this article: Palacios-García JM, Moreno-Luna R, Molina- \\
Fernandez E, et al. Bilateral Involvement of Frontal Sinuses in a Pott's \\
Puffy Tumor: A Case Report. Int J Otorhinolaryngol Clin 2019;11(3): \\
$67-69$. \\
Source of support: Nil \\
Conflict of interest: None
\end{tabular}

of continuity at the right frontal level was objected, but after its canalization, it was objected that each hole led to a frontal sinus and each one to its corresponding fossa (Fig. 3). The microbiological culture of pus obtained in the operating room isolated Streptococcus intermedius. The antibiogram showed sensitivity to penicillin, tetracycline, and levofloxacin. However, this showed resistance to clindamycin and erythromycin. Therefore, the change from antimicrobial treatment was made to levofloxacin $500 \mathrm{mg}$ every 12 hours.

After 4 days of hospital observation, the patient remained asymptomatic, so he was discharged with the same treatment for one more week. It was reviewed in consultations at the 15th days, not having presented relapsed or other associated symptomatology. At 6 months of follow-up, the patient remains asymptomatic. The patient gave informed consent for the publication of this case.

\section{Discussion}

Pott's puffy tumor is more frequent in male teenagers as in our report. ${ }^{3}$ This age group is the most susceptible to its development due to the embryological development of the frontal sinuses and 


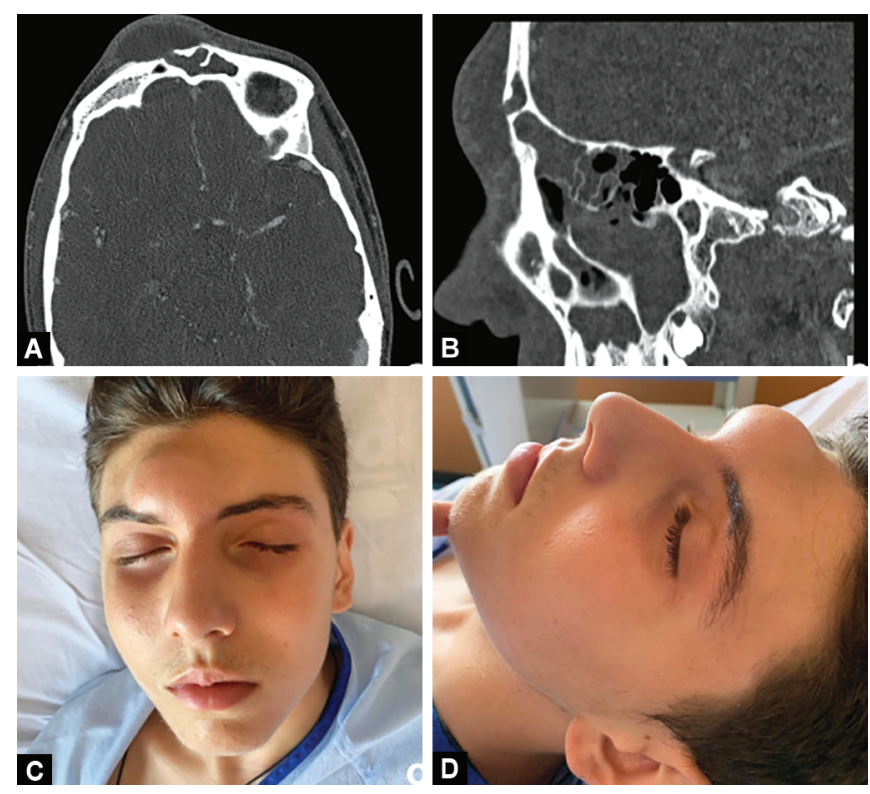

Figs $1 \mathrm{~A}$ to $\mathrm{D}$ : (A) Axial computed tomography demonstrating the defect in the temporal bone and the subperiosteal abscess; (B) Sagittal computed tomography demonstrating the defect in the temporal bone and the subperiosteal abscess; (C and D) Photograph was taken at the time of presentation showing right forehead swelling

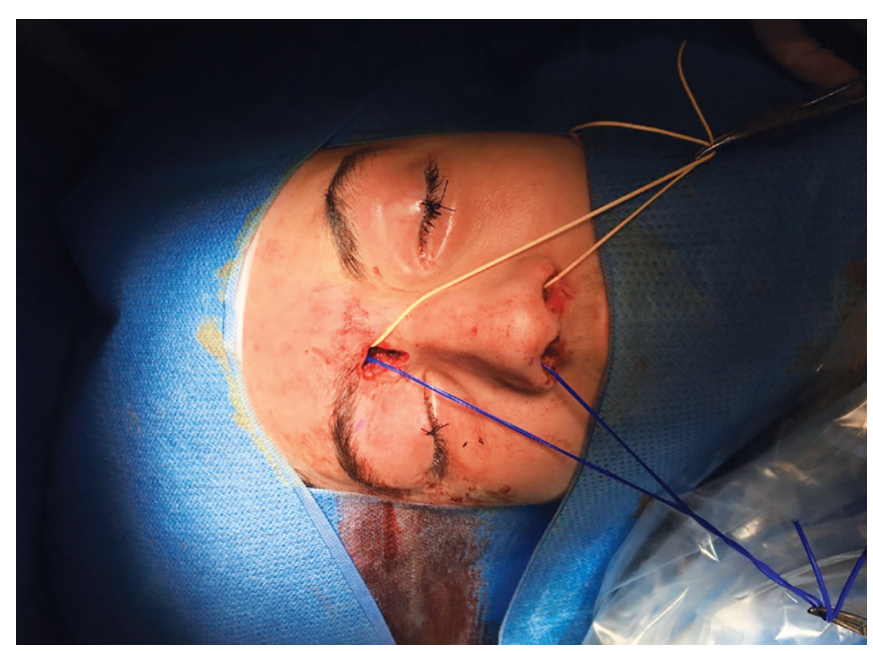

Fig. 3: Intraoperative image with canalization of each bone defect to a frontal sinus (in blue right frontal sinus and yellow left frontal sinus)

the presence of the frontal diploic veins, which encourage the spread of the infection. ${ }^{4}$ The involvement of both frontal sinuses in the production of Pott's tumor has never been described before. The main pathway of the spread of infection is usually the anterior wall of the frontal sinus. This leads to erosion of the external frontal bone with the development of a subperiosteal abscess. ${ }^{5}$ Probably, the osteomyelitis bone was the mechanism by which the anterior wall defect occurred in both sinuses.

Due to this pathology, it is a risk factor for intracranial complications, such as, extradural abscess, subdural empyema, and intracerebral abscess. ${ }^{6}$ The therapeutic intervention should be instituted early to avoid these complications. Given the need to evacuate the purulent collection, the most important point of the treatment is surgical. This can be endoscopic, external, or a

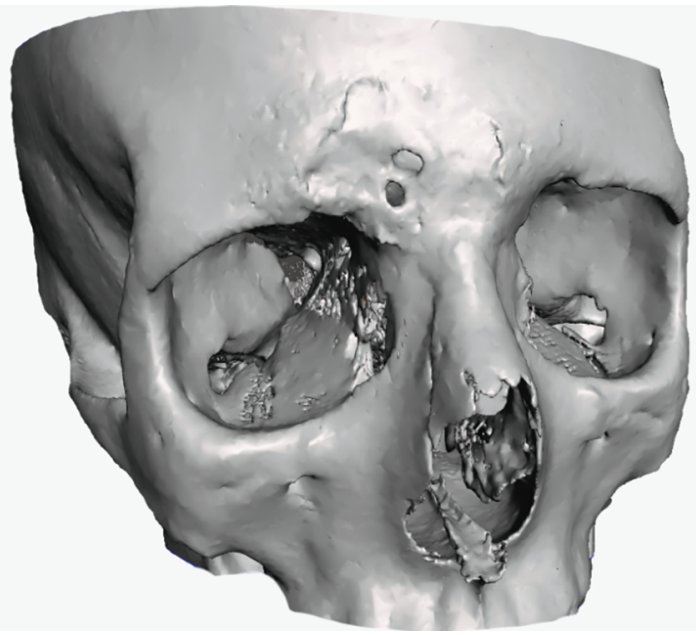

Fig. 2: 3D reconstruction showing the two defects in the frontal bone

combination of both. ${ }^{3}$ In our case, it was necessary to combine both the endoscopic and a minimal external approach to ensure complete cleanliness of both frontal sinuses. After the bilateral execution of draft lla and the exit of purulent material from both sinuses, the fluctuation of the abscess was partially maintained. Therefore, it was required an external modified Lynch-Howarth eyebrow incision approach to complete the sinus evacuation. This type of external approach, being so minimal, has practically no esthetic repercussion. More aggressive techniques, such as, draft III, should be reserved for revision cases or poor evolution has given the added morbimortality of this technique. ${ }^{7}$

Although magnetic resonance imaging (MRI) is more useful for delimiting soft tissue inflammation and brain involvement. The use of CT scanners is essential in these cases because it will provide us accurate images of bone and soft tissue. ${ }^{8}$ In addition, 3D images are increasingly important for surgical planning offering a more realistic image of the patient's anatomy. ${ }^{9}$ The $3 \mathrm{D}$ evaluation gave us a detailed idea of the bone state and its defects before surgery.

The group of microorganisms most frequently isolated are from the Streptococcus spp. ${ }^{2}$ In our case, it was so, being isolated S. intermedius which belongs to the Streptococcus anginosus group. These bacteria to differences of others of the Streptococcus spp. are related to a higher complication rate in rhinosinusitis, with greater intracranial involvement and the need for more aggressive treatment, both surgical and antibiotic therapy. ${ }^{10}$ This should be taken into account due to the use of the multivalent pneumococcal vaccine has changed the bacteriology of rhinosinusitis. ${ }^{11}$

Hence, the treatment must be directed against the causal microorganism. Besides, it is controversial whether long-term antimicrobial therapy is needed in acute osteomyelitis. ${ }^{12}$ Our treatment scheme is a surgical cleaning of the frontal sinuses and affected bone tissue accompanied by specific antimicrobial treatment for 15-20 days.

Therefore, a patient with this pathology should not be underestimated and the medical and surgical treatment should be started as soon as possible to avoid complications.

\section{Conclusion}

It is very important that in the case of an adolescent patient with a frontal tumor, this pathology is kept in mind. The 3D reconstructions of CT before surgery will help us in the surgical planning. Surgery 
should be the most important factor in the treatment of this disease together with a targeted antibiotic treatment.

\section{References}

1. Kim H-Y, Hwang EH, Han YM, et al. Pott's puffy tumor in an adolescent boy. Pediatr Int 2012;54(1):158-160. DOI: 10.1111/j.1442200X.2011.03419.x.

2. Koltsidopoulos $P$, Papageorgiou E, Skoulakis C. Pott's puffy tumor in children: a review of the literature. Laryngoscope 2018. 1-7.

3. Palabiyik FB, Yazici Z, Cetin B, et al. Pott puffy tumor in children: a rare emergency clinical entity. J Craniofac Surg 2016;27(3):e313-e316. DOI: $10.1097 /$ SCS.0000000000002573.

4. Clayman GL, Adams GL, Paugh DRKCJ. Intracranial complications of paranasal sinusitis: a combined institutional review. Laryngoscope 1991;101(3):234-239. DOI: 10.1288/00005537-199103000-00003.

5. Akiyama K, Karaki M, Mori N. Evaluation of adult pott's puffy tumor: our five cases and 27 literature cases. Laryngoscope 2012;122(11):2382-2388. DOI: 10.1002/lary.23490.

6. Dusu K, Chandrasekharan D, Al Yaghchi C, et al. A huge Pott's puffy tumour secondary to pansinusitis. BMJ Case Rep 2019;12(4):e229755. DOI: 10.1136/bcr-2019-229755.
7. Moser R, Schweintzger G, Uggowitzer M, et al. Recurrent Pott's puffy tumor - atypical presentation of a rare disorder. Wien Klin Wochenschr 2009;121(21-22):719-722. DOI: 10.1007/s00508-0091268-6.

8. Olmaz B, Cingoz M, Akdogan $E$, et al. Correlation of imaging and intraoperative findings in Pott's puffy tumour. Scott Med J 2019;64(1):25-29. DOI: 10.1177/0036933018803787.

9. Sánchez-Gómez S, Herrero-Salado TF, Maza-Solano JM, et al. Mejora de la planificación de las cirugías endoscópicas nasosinusales a partir de imágenes en 3 dimensiones con Osirix ${ }^{\circledast}$ y estereolitografía. Acta Otorrinolaringológica Española 2015;66(6):317-325. DOI: 10.1016/j. otorri.2014.10.002.

10. Deutschmann MW, Livingstone $\mathrm{D}, \mathrm{Cho} \mathrm{JJ}$, et al. The significance of Streptococcus anginosus group in intracranial complications of pediatric rhinosinusitis. JAMA Otolaryngol Head Neck Surg 2013;139(2):157-160. DOI: 10.1001/jamaoto.2013.1369.

11. Benninger MS, Manz R. The impact of vaccination on rhinosinusitis and otitis media. Curr Allergy Asthma Rep 2010;10(6):411-418. DOI: 10.1007/s11882-010-0139-6.

12. Huang $\mathrm{CY}, \mathrm{H}$ sieh RW, Yen HT, et al. Short- versus long-course antibiotics in osteomyelitis: a systematic review and meta-analysis. Int J Antimicrob Agents 2019;53(3):246-260. DOI: 10.1016/j. ijantimicag.2019.01.007. 